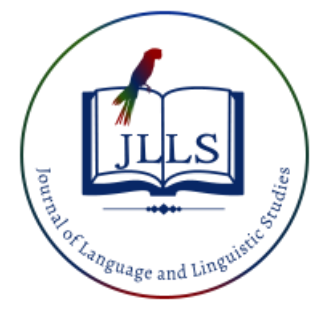

Available online at www.jlls.org

JOURNAL OF LANGUAGE AND LINGUISTIC STUDIES

ISSN: 1305-578X

Journal of Language and Linguistic Studies, 17(3), 1258-1265; 2021

\title{
"No trolls left behind!": Using films to address communication apprehension in the English language classroom at Universiti Utara Malaysia
}

\author{
Azrina Abdul Razak a ${ }^{\text {ID }}$, Hariharan N Krishnasamy ${ }^{\text {b iD, Norzanita Othman }}{ }^{c}$ iD \\ ${ }^{a, b, c}$ Univerisiti Utara Malaysia, Malaysia
}

\section{APA Citation:}

Abdul Razak, A., Krishnasamy, H.N., Othman, N. (2021). "No trolls left behind!”: Using films to address communication apprehension in the English language classroom at Universiti Utara Malaysia. Journal of Language and Linguistic Studies, 17(3), 1258-1265. Doi: $10.52462 /$ jlls. 89

Submission Date:20/04/2021

Acceptance Date:05/08/2021

\begin{abstract}
Silence in the English language classroom is a common problem faced by language instructors, especially for students in the lower proficiency classes and instructors see language anxiety as one of the main reasons this is so. The intervention of educational entertainment or Edutainment in the English Language classroom is important to improve the language learning experience of this generation of millennial students. This paper looks at Films to provide not only language learning enjoyment but useful input to students of the lowest level English course at UUM. In this research, intervention in the form of film viewing and activities related to the films was carried out. A class of twenty students from a first level English class weregiven six movies of their choice to watch and conduct activities with in addition to the normal course scheme of work. Through film viewing and activities, students were exposed to language use in context which is supported by visual and linguistic support and storyline. Before and after the intervention, The Personal Report of Communication Apprehension (PRCA24) instrument which measures levels of Communication Apprehension was administered. The results of the study shows that students indicated lower communication apprehension levelsoverall and within the subcategories of group discussion, meetings, interpersonal communication and public speaking. Students' reflections were also positive in nature. The findings of this study concur that language acquisition takes place meaningfully through films by providing comprehensible input and that films are an important medium that facilitate communication and language learning for this generationof students.
\end{abstract}

Keywords: SLA; language anxiety; edutainment; communication apprehension; classroom

\section{Introduction}

Many strides have been taken to improve the standard of English at all levels in Malaysia. In addressing the issue of the deterioration of the standard of English, Malaysian public universities have implemented the new curriculum, which places the development of students' communicative competence as one of its main objectives. Nikitina \& Furuoka (2012) conducted a study on Malaysian undergraduates and found that the inclusion of soft skills as an important aspect to better improve on the current Malaysian policy. This has been inherently done because in Malaysia, graduates are said to

\footnotetext{
${ }^{1}$ Corresponding author.

E-mail address: azrina.abdul.razak@gmail.com
} 
perform well academically but have poor spoken and written English competence and this becomes a stumbling block for them to successfully attain a job or advance in their careers. The levels of communicative competence in English is considerably low even though language proficiency and communicative skills are competitive factors to be employed (Darmi, R., 2013). In the classroom, students often have the tendency to remain silent or shy when they are supposed to participate in discussion. This study attempts to address students' poor oral communicative competence in the english language clasroom by focussing on Communication Apprehension (anxiety).

The students selected are from English for Proficiency I, whereby their MUET test scores are in Band 2. According to the MUET rubrics, these students are limited users of English with very limited ability to functon in the language. They have very limited understanding of the English language and context. In terms of Communicative ability, they are hardly able to function using English as they lack expressiveness, fluency and appropriacy. This often results in communication breakdown. English for Profciency I, is a pre-intermediate course which mainly introduces basic communication skills using the four modes of speaking, listening, reading and writing. Emphasis is placed on the development of oral communication skills of listening and speaking. The language tasks and activities should develop students' interpersonal communication skills. Therefore, upon completion of the course, students of English for Proficiency I should be able to express their opinions on issues discussed orally. When reading and listening, they should be able to identify main ideas and specific information. They are also expected to be able to use approriate grammar and vocabulary in speaking and writing tasks.

As a language instructor for English for Proficiency I, I have found that students have difficulties in communicating with others such as in expressing ideas, thoughts and views when assigned tasks. This is more evident during pair-work or group-work. Students find diffculty in using the right words and often feel stressed because of their lack of proficiency in English. I also often come across students who remain passive or silent. This could be attributed to the anxiety and stress of using a language which is not used regularly. Furthermore, students find it a challenge to apply their limited knowledge of English in actual classroom discussions. There is a need to look into these problems associated with anxiety and communicative ability.

\section{English Language Anxiety (Language Apprehension)}

Exposure to the English language for many Malaysians starts as early as age 6 and 7 since English is a subject taught at their respective schools. However, because contact with the language is limited to the English Language classroom only, most students' input of the language is insufficient to be used as a medium for ordinary communication. So, where everyday life is concerned, the mother tongue is still preferred and situations which require the use of English posits much anxiety.

McCroskey (1984) defined communication apprehension as having a fear of engaging or anticipating in communication. When people experience fear in communicating, they tend to withdraw themselves from participating in discussions and they also tend to be more reserved when communicating. Communication Apprehension is also referred to as stage fright or performance anxiety. Wan Zumusni et. al (2010) conducted a study on final year students of Bachelor of Business Administration in one of the local universities in Malaysia and found that students who scored 80 marks and above in the PRCA-24 communication apprehension instrument disliked participating in group discussions. They also were reported as being nervous and tensed when speaking with unfamiliar people in group discussions.

One way of reducing communication apprehension among students is through incorporating the aspect of edutainment within the classroom setting. Watching movies as part of the learning activities could provide immense opportunities for learners to acquire language skills (Alluri, 2018), especially 
to develop aural and oral skills. The process of watching movies enriches the audio-visual experience in which students listen to communication in context. This pedagogical approach provides exposure to students to learn the target language implicitly in a fun and meaningful way. Furthermore, watching movies need not be confined to classroom hours and students can access the movie at a time that is convenient to them (Nath, Mohamad, \& Yamat, 2017). By making the language learning classes more enjoyable, students would be more interested to learn language and indirectly will reduce their level of apprehension in communicating.

King (2002) suggests that featuring films that relate to real life contexts that students can relate to would engage their interest, increase motivation to acquire the language, observe the communication events and be immersed in the English language world.

\section{Using Films to Reduce Students' Level of Anxiety (Communicative Apprehension) in the English Language Classroom}

A number of studies had confirmed the advantages on the use of films in the EFL classroom. Stempelski (2000); Cross (2011) and Mekheimer (2011) investigated on the use of films in language teaching. Aliyev \& Albay (2016) developed a study based on Krashen's input hypothesis, which affirms that language is acquired by receiving comprehensible input. Their study showed that "films were necessary tools in language learning since they provide language learners meaningful comprehensible input." These researchers agree on the benefits of film in the language learning environment. Films are essential materials in a language lesson that "provide more pedagogical options and are a rich resource of intrinsically motivating materials for learners" (King, 2002, p.1). Khan (2015) considers film a perfect fit to students' lives since integrating them in language classroom are motivating and makes the language learning enjoyable.

This study, which focuses on the use of films in the classroom is instrumental in engaging students to learn English in a more holistic manner. Films make learning fun and meaningful. The use of films is ideal and meaningful by exposing everyday situations and the use of appropriate language forms, features and structures. Traditionally, films have been associated with entertainment and leisure. Many students are willing to pay to watch films. However, films need not be confined to entertaiment but can also serve as a useful tool for language learning in a more stress-free or anxiety-ridden environment. The potential use of this form of edutainment can be used to enhance the language learning experience. Films provide useful input as students are exposed to language use in context (Seferoglu, 2008). The situation in which it is used is supported by visual and linguistic support and storyline. Characterisation, plot and setting give useful pointers for understanding the words and communication in context. Thus, films will be used as a teaching and learning tool to help reduce student anxiety in line with the communicational objectives of this course.

\section{Design of the Study}

In this case study, intervention in the form of film viewing and activities related to the films was carried out. A mix-method approach was used in order to answer whether film viewing helps to lower students' communication apprehension via quantitave and qualitative data and the interpretations derived from integrating the strengths of both sets of data in presenting a complete comprehension of the research problem (Creswell, 2015). McCroskey's The Personal Report of Communication Apprehension (PRCA-24) instrument was administered before and after the intervention to answer to what extent the students felt about communicating with others. The PRCA-24 instrument is most widely used to measure communication apprehension because it is highly reliable (alpha regularly >.90) and has very high predictive validity. This instrument allows researchers to see CA levels within 
sub-scores on the contexts of public speaking, face-to-face interaction, small groups, and large groups. Participants answered the questions in the questionnaire and their responses were analyzed using descriptive statistics. To find out about how students felt about the film viewing and the activities being carried out, the qualitatative approach was used. Students were informed to keep a reflective journal to write about their feelings, thoughts and views about their experience throughout the intervention.

The participants in this case study were a class of twenty undergraduate students from the lowest level of english class - English for Proficiency I at Universiti Utara Malaysia. This is a preintermediate proficiency course which introduces students to basic communication skills in an integrated manner, using the four skills of speaking, listening, reading and writing. Emphasis is placed on developing oral communication skills and students are expected to practise using English in a wide variety of social contexts.

Data collection was carried out throughout the 14-week semester. Since the intervention was conducted out-of-class, a panel consisting of two senior lecturers suggested that students would meet every other week. Therefore, students were given six films to watch and conduct activities together with in addition to the normal course scheme of work. The criteria set to select the films were based on appropriate language used in day-to-day communication. This is in line with the objectives of the course. The titles were selected by the students themselves and this motivates them to attend the sessions as they were eager to watch the films.

The study used steps suggested by Seferlogu (2008) for using feature films in the classroom. Firstly, there were previewing activities or warming up activities like an explanation about the film and its genre. Students were told to write down key vocabulary and expressions which hindered their understanding of certain scenes. Next, they were given worksheets which required them to answer short questions. After viewing the film comes the movie summaries. Students were asked to write one short review for any of the movies they watched. Group work \& a role-play came in last. Students would sing along to the soundtrack of the films or role-play certain favorite scenes. The students also kept a reflective journal to write about their thoughts and views about the films and the activities conducted in each session.

\section{Results of Prca-24}

Results of pretest score for this group is as follows:

\begin{tabular}{|l||l||l|l|}
\hline \hline & Mean & High & Low \\
\hline \hline Total Score: & 83.4 & $>104$ & $<70$ \\
\hline \hline Group: & 19.7 & $>25$ & $<13$ \\
\hline \hline Meeting: & 23.3 & $>26$ & $<12$ \\
\hline \hline Interpersonal: & 24.1 & $>27$ & $<17$ \\
\hline \hline Public: & 25.1 & $>27$ & $<17$ \\
\hline
\end{tabular}

Total score for pretest is 83.4. This falls under the category of high level of communication apprehension as indicated by McCroskey. Within the subcategories of group discussion, meetings, interpersonal conversation and public speaking, McCroskey stated that any score above 18 is indicative of some degree of apprehension. The range is from low of 6 to high of 30. As seen in the pretest, students indicated a mean score of 19.7 for group discussion, 23.3 for meetings, 24.1 for interpersonal conversations and 25.5 for public speaking. All scores in these contexts are more than 18 
which means that apprehension levels in the subcategories of group discussion, meetings, interpersonal conversation and public speaking are all high.

Results of postest score for this group is as follows:

\begin{tabular}{|l|l||l|l|}
\hline & Mean & High & Low \\
\hline \hline Total Score: & 60.9 & $>74$ & $<48$ \\
\hline Group: & 12.1 & $>16$ & $<10$ \\
\hline Meeting: & 16.0 & $>20$ & $<12$ \\
\hline Interpersonal: & 15.0 & $>21$ & $<12$ \\
\hline Public: & 17.8 & $>24$ & $<11$ \\
\hline
\end{tabular}

Total score for the posttest is 60.9. This is within the moderate level of communication apprehension. As previously stated, McCroskey indicated that in these subcategories any score above 18 indicates some degree of apprehension. In the subcategory of group discussions, the mean score is 12.1. For meetings, students indicated an average score of 16. Interpersonal interactions recorded a mean score of 15 and for public speaking, 17.8. All scores indicated within these contexts are all below 18. This indicates low apprehension levels.

To review students' reflection, qualitative content analysis was used to identify themes arising from the data. Students were not able to fully reflect on their learning experience but recurrently stated their contentment in watching the films and doing the in-class activities together as a group. Themes which emerged mainly were on plot restatement and fun watching.

I love this movie! I hope to watch it again because it is interesting;

Today's class is not boring at all;

I truly enjoyed watching this animation film.;

I am so glad we watch films during extra class.;

Thank you to my lecturer because we watch movies.

The theme of interesting and less stress in class also emerged.

Students including me will get bored if we keep learning the same way;

I am glad we get to experience learning English like this.;

Doing activity like this help us increase our focus and I don't feel afraid to speak.

\section{Discussion}

This study on the use of films in the classroom for reducing communication apprehension provides useful input in enhancing students' learning experiences. The results have shown that watching movies is effective in reducing communication apprehension. In order to improve English language learning, the language input has to occur in an environment that minimizes stress rather than one where levels of communication apprehension are high.

The study has statistically proven that with the intervention program, communication apprehension shifts from a higher range to a lower range. A comparison between the pretest and the posttest scores shows a marked shift in the total mean score from 83.4 to 60.9. This is a significant difference of more than 20 points. Furthermore, the mean scores have shown a consistent pattern in which the post test scores are lower for group discussion, meetings, interpersonal conversations and public speaking. Communication apprehension pre test scores are 19.7 for group discussion, 23.3 for meetings, 24.1 for interpersonal conversations and 25.5 for public speaking. In comparison, post test scores for the same categories are 12.1, 16, 15 and 17.8 respectively. These scores provide an important indicator of the 
levels of communication apprehension as a score 18 is an important demarcation point in McCroskey's scale which covers a range between 6 to 30. Scores above 18 indicate higher degrees of apprehension during the pretest while those below 18 indicate lower degrees of apprehension during the posttest. The detailed scores for each subcategory confirm that communication apprehension levels among students became lower after the intervention.

Relevant studies in the literature emphasized the advantages on the use of films for students who do not use English as their first language (Stempelski, 2000; Cross, 2011; Mekheimer, 2011). This study concurs with findings from previous studies that films are useful in language teaching and learning (Nath, et. al., 2017). Films facilitate learning and communication as they are a medium in which language is used in context (Seferoglu, 2008). From the theoretical perspective, the findings of this study are similar to Aliyev \& Albay's (2016) study based on Krashen's input hypothesis. Language acquisition takes place meaningfully through films which provide comprehensible input. There is general consensus that films are an important medium that facilitate communication and language learning.

Thus the researchers' intervention via film viewing activities contributed to the positive development of students' communication skills. Although participation was limited to 20 students, the comparison between students' scores in the pre and posttest using McCroskey's (PRCA-24) was consistent across the four categories, with significant decreases in communication apprehension levels. This is further evident form the students' reflection as they responded positively to the learning process and communication activities. The findings were similar to many previous studies that analyzed the important relationship between the use of films and communication apprehension under various categories. The findings in this study are consistent with findings from many previous studies in which films had a positive effect on reducing communication apprehension. The study also suggests that it is possible to use films during English language classes with an array of pedagogical options to be explored for different communication purposes (King, 2002).

\section{Conclusion}

In concluding, this study provides further evidence on the importance of using a media that reduces anxiety and stress among students in acquiring a second language. Students become better at communication when anxiety levels are lowered. Though English is recognized as a second language in Malaysia, some of the students view it almost as a foreign language. Stress and anxiety do not provide the appropriate classroom climate for language learning. Thus, it would be important to use films, which are often associated with fun, relaxation and entertainment to reach out to students. It has the potential to make English language learning fun and meaningful.

\section{References}

Aliyev, A. \& Albay, M. (2016). Bridging the Gap between Theory and Practice: The use of films in Language Learning. International Journal of Social Sciences \& Educational Studies, 2(3).

Alluri, P. (2018). Enhancing English Language teaching through Films in General Foundation Programs. Arab World English Journal (AWEJ). Proceedings of 1st MEC TESOL Conference 2018, 146-154.

Creswell, J. W. (2015). A concise introduction to mixed methods research. Thousand Oaks, CA: Sage.

Cross, J. (2011). Metacognitive instruction for helping less-skilled listeners. ELT Journal, 65(4), 408416. 
Darmi, R., \& Albion, P. (2013). English language in the Malaysian education system: Its existence and implications. In Proceedings of the 3rd Malaysian Postgraduate Conference (MPC 2013), 175183. Education Malaysia.

Nikitina, L. \& Furuoka, F. (2012). Sharp focus on soft skills: A case study of Malaysian university students' educational expectations. Education Research for Policy and Practice, 11, 207-224.

Khan, A. (2015). Using films in the ESL classroom to improve communication skills of non-native learners. ELT Voices- International Journal for Teachers of English, 5(4), 46-52.

King, J. (2002). Using DVD feature films in the EFL classroom. The Weekly column, Article88. http://www.eltnewsletter.com/back/ February2002/art882002.htm

Krashen, S. (1985). The input hypothesis: Issues and implications. New York: Longman.

Leeds, M.L \& Maurer, R.A. (2009). Using Digital Video Technology to Reduce Communication Apprehension in Business Education. INFORMS Transactions on Education, 9(2), 84-92.

McCroskey J.C., Beatty M.J. (1986). Oral Communication Apprehension. In: Jones W.H., Cheek J.M., Briggs S.R. (eds) Shyness. Emotions, Personality, and Psychotherapy. Springer, Boston, MA.

McCroskey, J. C. (1982). An introduction to rhetorical communication (4th Ed). Englewood Cliffs, NJ: Prentice-Hall. (Also available in more recent editions of this book, now published by Allyn \& Bacon.)

Mekheimer, M. (2011). The impact of using videos on whole language learning in EFL context. Arab World English Journal, 2(2), Retrieved on 12 December, 2016 fromhttp://www.awej.org/awejfiles/_42_5_4.pdf

Nikitina, L., Furuoka, F. (2012). Sharp focus on soft skills: a case study of Malaysian university students' educational expectations. Educ Res Policy Prac, 11, 207-224. https://doi.org/10.1007/s10671-011-9119-4

Nath, P., Mohamad, M., \& Yamat, H. (2017). The Effects of Movies on the Affective Filter and English Acquisition of Low-Achieving English Learners. Creative Education, 8(8), 2151-4755.

Seferoğlu, G. (2008). Using feature films in language classes. Educational Studies, 34(1), 1-9, DOI: $10.1080 / 03055690701785202$.

Stempelski, S. (2000). Video in the ESL classroom: Making the most of the movies. ESL Magazine, March/April, 10-12.

Wan Zumusni et. al. (2010). ESL Students communication apprehension and their choice of communicative activities. AJLTHE, 2(1), 22-29.

\section{AUTHOR BIODATA}

Azrina Abdul Razak is a lecturer at the School of Creative Industry Management and Performing Arts (SCIMPA) in Universiti Utara Malaysia. She holds a Bachelor's Degree in English from Pennsylvania State University and Master's in Film Studies from University College Dublin. Her career as an academic spans over 20 years. She has taught and supervised students at both the undergraduate and postgraduate levels and has cowritten several English modules and textbooks used for both on-campus and off-campus undergraduate programs at Universiti Utara Malaysia. Her research interests include teaching English as a second language, communication, creative industry, creative economy, creative arts, and film.

Associate Professor Dr. Hariharan N Krishnasamy teaches at the School of Languages, Civilisation and Philosophy in Universiti Utara Malaysia. In an educational career spanning more than 30 years, he has taught 
several courses including Academic Writing, Semantics and Sociolinguistics. He has been involved in soft skills training programs for students and conducted courses on Intercultural Communication, Public Speaking, as well as the use of IT for teaching purposes. He has also been a mentor for trainee teachers and lecturers in various fields. His research interests include rural education, education for indigenous peoples, communication, and teaching English as a second language. Among his other academic engagements include supervising postgraduate students from various countries, and giving talks on research.

Norzanita Othman is a faculty member of Applied Linguistics Unit, School of Languages, Civilization and Philosophy, Universiti Utara Malaysia. She has taught subjects at the undergraduate and postgraduate level. Her areas of interest is discourse analysis specifically studies on language and gendered violence. 